\title{
Nomophobia: An Assessment of No Phone Phobia among Adolescents
}

\author{
Gaurav Kohli ${ }^{1}$, Manu Kohli ${ }^{2}$, Poonam Joshi ${ }^{3}$ \\ ${ }^{1}$ Gaurav Kohli, Professor, Chitkara School of Health sciences, Punjab, India, ${ }^{2}$ Manu Kohli, Associate Professor, \\ Chitkara School of Health Sciences, Chitkara University, Punjab, India, ${ }^{3}$ Poonam Joshi, Assistant Professor, Guru \\ Hargobind College of Nursing, Raikot, Punjab, India
}

\begin{abstract}
Nomophobia is a fear of being without mobile phone and it's like fear of losing phone, checking it for call but it's not ringing, mobile gaming and engage in social sites at maximum. This was a study to assess nomophobia among adolescents. The aim of study was to identify the mobile usage pattern and risk of developing nomophobia among the college students. The selected Setting was college of Education Halwara, Ludhiana, Punjab. A non-experimental/exploratory research design was utilized and 80 Elementary teacher training students were selected through consecutive sampling technique. A self - reporting checklist was utilized to assess the mobile usage pattern and rating scale assessed the risk of developing nomophobia. Analysis was done using SPSS 16.0 version. Descriptive and inferential statistics were used to analyze the data. The findings indicated that the maximum 55 (68.25\%) of students follows the normal mobile usage pattern similarly the maximum $67(83.75 \%)$ of participants were at the lower risk of developing nomophobia. There was moderate uphill (positive) relationship between the mobile usage pattern and risk of developing nomophobia.it is concluded that informative material and sensitizing sessions can help the students to cope up with this addiction.
\end{abstract}

Keywords: Nomophobia, mobile, mobile addiction, smart phone, adolescents.

\section{Introduction}

In the era of technology, our affections are flowing more toward gadgets than humans. Similarly, youngster's love for mobile has increased to the maximum, which is making them weaker in certain spheres of life. The word nomophobia designed for mental health problem arises from mobile usage, which is an existence of self without phone or fear of losing phone. Nomophobia also known as no-mobile phobia, which may come in situation like no network area, not recharged, battery discharged, misplaced or any other. ${ }^{1}$ The new age mobile phone has replaced various things (diary, computer, calculator, music player, camera, video game, mode of entertainment, concerns, conversations and group involvements) of our lives, which are also predisposing causes of this irrational apprehension of being without phone. $^{2}$

The reckless use of mobiles is unfolding the barriers to social and parental control. It's a free zone to share the views, ideas and imaginations with peer groups. Secondly, it's a major status symbol among youngsters in this era. Due to this boundary free approach, the dependency is taking toll on physical, mental, social and financial health of youngsters. Modern mobile phones are recognized as new epidemic disease of the century and the students are main affected chunk of it. It is quoted as a best measure to use in study in terms of material accessibility but more than serving the purpose it exposes our young population to its addiction. New platform of mobile phones like android can help the students in many domains of the study as comes with educational apps but it also pushing the students toward mental dependence toward mobile phones. ${ }^{3}$

According to data regulatory authority of India there are about 1.18 billion mobile users in India and the age group of 19-24 years reveals the high degree of penetration in usage. They show significant inclination for their own mobile phones. 2 out of 3 mobile users are unmarried or singles. ${ }^{4} \mathrm{~A}$ study revealed that the 
excessive use of mobile phone among teenagers results in restless, fatigue and insomnia. Findings of the study highlighted the percentile of mobile utilization in various life routines as $58 \%$ Indian users utilize it to maximum during air travel, $69 \%$ in cinema halls, $21 \%$ on religious place, $79 \%$ on weddings ceremonies, $25 \%$ in shopping and last $80 \%$ Indian use it on dining table. According to cross-sectional study, adolescents are mainly linked to the factors (depression, social separation, drug/alcohol use and academic failure) associated with intense mobile phone usage. The total number of 1328 samples with age limit of 31-20 years were selected in the study. The result shows that the factors like mobile phone possession is contributing to $96.5 \%$ (one phone $80.5 \%$ and $>1$ phone $15.9 \%$ ), carry to educational institution is $54.8 \%$, whereas $46.1 \%$ keep it on during the class even, extreme mobile dependence was calculated to $39.1 \%$ (26.1\% among females and $13 \%$ males). ${ }^{5}$

This investigation was conducted to assess mobile usage pattern and risk of developing nomophobia; to find out the correlation between mobile usage pattern and risk of developing nomophobia; to assess the relation between mobile usage pattern and risk of developing nomophobia with demographic variables. This original paper contributed to explore the most susceptible population to Nomophobia as they are the one who carried India to $2^{\text {nd }}$ rank among most gaming nations. This is a sign to explore this component of addiction prevailing with increased screen time. Researchers went through the facts available as well as carried out the investigation for same. This will help the research community to guide their investigations toward this important and less explored component of adolescents' mental health.

\section{Materials and Method}

A quantitative approach and an exploratory research design were adopted to identify the mobile phone usage and risk of developing nomophobia among students. The demographic variables of the study were age (in years), gender, father and mother education, Family monthly income, type of family and academic year, Research variables were mobile usage pattern and risk of developing nomophobia. The main study was conducted in Shri Guru Ram Dass College of Education, Halwara and sample of 80 students were selected with consecutive sampling technique. All the students were possessing smart phones and there was no exception. The tool consists of three parts i.e. sample characteristics; self-structured checklist to assess mobile usage pattern and self-structured rating scale to assess the risk of developing nomophobia. The criterion measure of tools was categorized as Mobile usage pattern checklist - Normal usage pattern and abnormal usage pattern, whereas rating scale to identify the risk of developing nomophobia was categorized as No risk, Lower risk and High risk. The tool was validated by 15 experts as well as calculated reliability of tool was 0.91 for checklist and 0.89 for rating scale. An approval was extended by the ethical committee of G.H.G College of Nursing. A written consent was taken from each participant after explaining theaim of study.An assurance was extended by the researchers about their responses will be confidential and utilized for research purpose. Researchers explained the rights to participants i.e. they can withdraw and refuse the answer as well as intervention wouldn't pose them to any physical, mental and social threat. Responses were recorded in one sitting and an average time taken by each student to mark their responses was 35-40 mins. Responses were analyzed with the help of descriptive and inferential statistics. The problem faced by the researcher to carry on this study was difficulty to get permissions as students were engaged in their coursework.

\section{Results}

Analysis and interpretations were carried out according to the laid down objectives of the study. The data was demographically distributed according to age (in years), gender, father's and mother's education, Residence place, Family monthly income, type of family and academic year. There were maximum 37 (46.25\%) students in the age group of 18-19 years followed by $30(37.5 \%)$ of students fall in 20 to 21 years of age, whereas minimum $13(16.25 \%)$ students were of $>21$ years. More than half $55(68.75 \%)$ students were females whereas minimum $25(31.25 \%)$ students were males. The maximum 39 (48.75\%) students' fathers were educated between 6 th -10 th followed by $19(23.75 \%)$ students' fathers were educated up to primary followed by $10(12.5 \%)$ students' fathers were educated between $10+1-10+2$ followed by $8(10 \%)$ students' fathers were illiterate whereas minimum $4(5 \%)$ students' fathers were educated up to graduation and above. The maximum 30 (37.5\%) students' mothers were educated between $6^{\text {th }}-10$ th followed by $22(27.50 \%)$ students' mothers were educated up to primary followed by 17 $(21.27 \%)$ of students' mothers were illiterate followed by $8(10 \%)$ students' mothers were educated between 
$10+1-10+2$ whereas minimum 3 (3.33\%) of students' mothers were educated up to graduation and above. The total $80(100 \%)$ students were residing at home and no one was living in hostel. There were 35 (43.75\%) students had $\leq 5000$ monthly family income followed by 34 (42.5\%) students had 5001-10000 monthly family income followed by 8 (10\%) students had 10001-15000 monthly family income whereas $3(3.33 \%)$ of students had $\geq 15001$ monthly family income. Nearly half 49
$(61.25 \%)$ of students belong to nuclear family followed by $30(37.5 \%)$ students from joint family whereas minimum $1(1.25 \%)$ students belong to extended family. The maximum 46 (57.5\%) students were studying in second year whereas $34(42.5 \%)$ students in first year of elementary teacher training course. Figure 1 reveals that the $55(68.25 \%)$ students follows the normal mobile usage pattern whereas minimum $25(31.25 \%)$ students were in the category of abnormal mobile usage pattern.

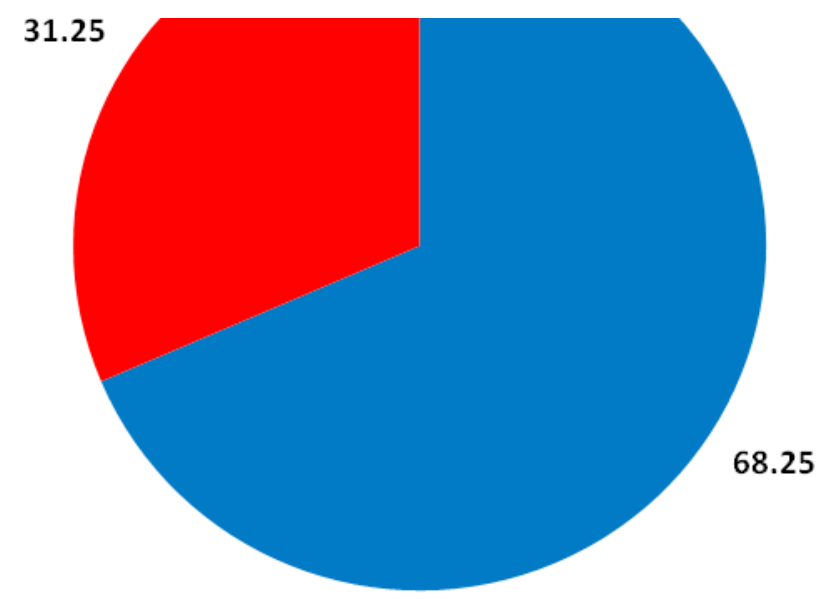

\section{Normal usage pattern}

- Abnormal usage pattern

Fig 1: Percentage distribution of mobile usage pattern

Figure 2 depicts that maximum 67 (83.75\%) students at the lower risk of developing nomophobia followed by $10(12.5 \%)$ students at higher risk, whereas $03(3.75 \%)$ students at no risk of developing nomophobia.

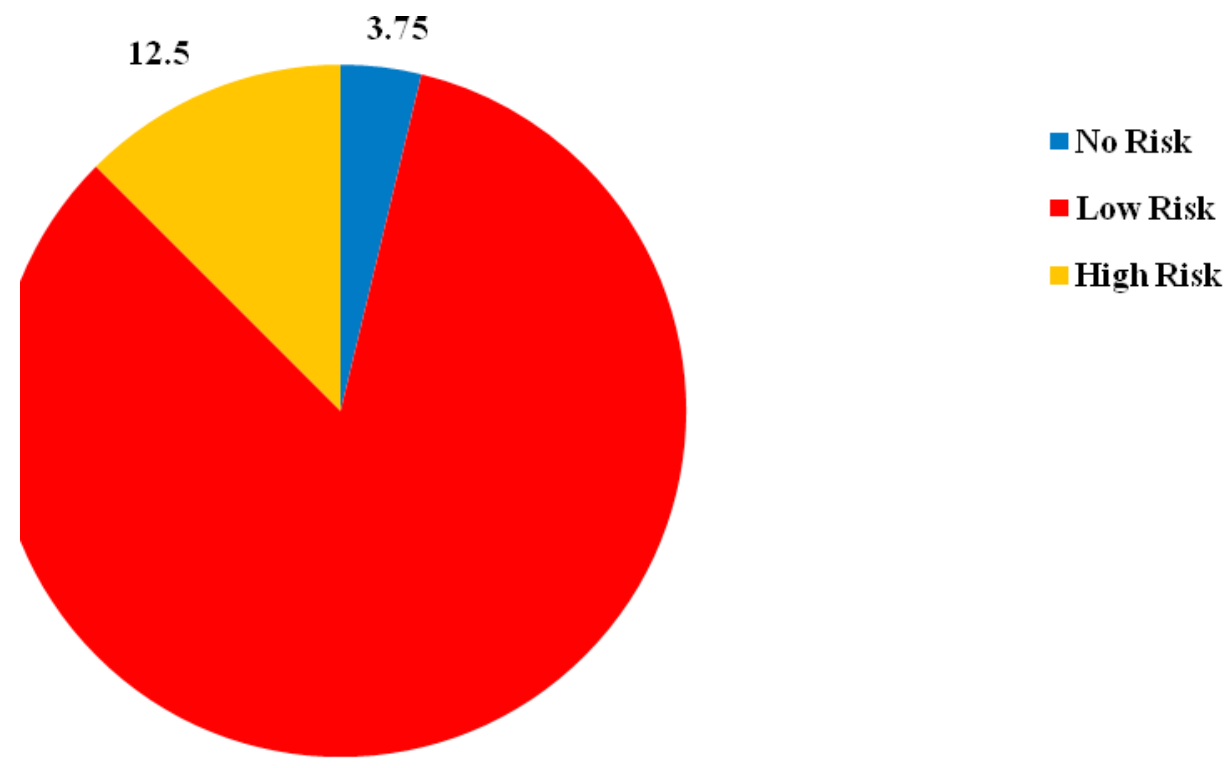

83.75

Fig 2: Percentage of risks of developing nomophobia

Table 1 depicts that the mean scores was 51.41 of students at risk of developing nomophobia, whereas the mean score was 9.16 for the mobile usage pattern of students. The calculated $\mathrm{r}$ value between mobile usage pattern and risk of developing nomophobia was 0.506 . Hence it was concluded that there was a moderate uphill 
(positive) relationship between the mobile usage pattern and risk of developing nomophobia among students.

Table 1: Correlation between mobile usage pattern and risk of developing nomophobia among students $(\mathbf{N}=\mathbf{8 0})$

\begin{tabular}{|l|c|c|c|}
\hline Correlation & N & Mean \pm SD & r \\
\cline { 1 - 3 } Mobile Usage Pattern & 80 & $9.16 \pm 2.65$ & \multirow{2}{*}{0.506} \\
\cline { 1 - 3 } $\begin{array}{l}\text { Risk of developing } \\
\text { nomophobia }\end{array}$ & 80 & $51.41 \pm 14.16$ & \\
\hline
\end{tabular}

Table 2 reveals the relationship between mobile usage and demographic variables. The calculated $\mathrm{F}$ and $t$ values of age (in years), gender, father and mother education, Family monthly income, type of family and academic year found no significantat $\mathrm{p}<0.05$, which means there was not significant relationship between the variables.

Table 2: Relationship between mobile usage pattern with demographic data $(\mathrm{N}=\mathbf{8 0})$

\begin{tabular}{|c|l|c|c|}
\hline Sr.No. & Demographic data & F value & P value \\
\hline 1 & Age & 0.27 & 0.760 \\
\hline 2 & Gender & 0.19 & 0.421 \\
\hline 3 & Father's education & 0.06 & 0.992 \\
\hline 4 & Mother's education & 0.64 & 0.635 \\
\hline 5 & Family income & 0.74 & 0.528 \\
\hline 6 & Type of family & 0.70 & 0.496 \\
\hline 7 & Academic year & 0.80 & 0.372 \\
\hline
\end{tabular}

$\mathrm{F}-\mathrm{F}$ value, $\mathrm{t}-\mathrm{t}$ value, $\mathrm{p}<0.05$

Table 3: Relationship between risk of developing nomophobia with demographic data $(\mathrm{N}=\mathbf{8 0})$

\begin{tabular}{|c|l|c|c|}
\hline Sr.No. & Demographic data & F value & P value \\
\hline 1 & Age & 0.866 & 0.424 \\
\hline 2 & Gender & $5.881 *$ & 0.001 \\
\hline 3 & Father's education & 0.956 & 0.436 \\
\hline 4 & Mother's education & 0.742 & 0.566 \\
\hline 5 & Family income & 2.110 & 0.105 \\
\hline 6 & Type of family & 5.220 & 0.190 \\
\hline 7 & Academic year & 2.242 & 0.138 \\
\hline
\end{tabular}

$\mathrm{F}-\mathrm{F}$ value, $\mathrm{t}-\mathrm{t}$ value, * significant at $\mathrm{p}<0.05$

Table 3 depicts the relationship between risk of developing nomophobia with demographic variables. It reveals that the calculated $\mathrm{F}$ values betweenage (in years), father and mother education, Family monthly income, type of family and academic year found no significant relationship with risk of developing nomophobia. The calculated $t$ value between gender and risk of developing nomophobia had shown significant relations.

\section{Discussion}

The findings of study were supported by Salloju V, Ranjith B (2017) ${ }^{6}$, the cross-sectional study was conducted to assess the severity of mobile dependency among 171 pharmacy students. The target age group was $17-25$ years. Findings show that only $24.37 \%$ of pharmacy students had risk of developing nomophobia. George S, Saif N, Joseph B (2017) ${ }^{7}$ supports the findings of study, topic was to find the utilization of mobile among medical students in Kerala, which shows that only $35 \%$ of medical students are frequent mobile users, whereas $65 \%$ were normal mobile users. Similarly finding were reported by Kaur A, Sharma P $(2015)^{8}$ an investigation was conducted to find out the threat of producing nomophobia among students of nursing. The findings suggested that there was moderate correlation of mobile use andthreat of producing nomophobia. Mertkan D Gezgin, OzlemCakir $(2016)^{9}$ conducted an investigation to find out theprevalence of nomophobia in pre-service teachers of Trakya university and results concluded that age has relationship with the mobile usage pattern in preschool teachers. Datta S, Nelson V, Simon $\mathrm{S}(2016)^{10}$ who conducted a study to assess the mobile use and problems reported by the students of medical education. Findings concluded that father's education has no association with mobile usage pattern in medical students. Prasad M, Patthi B, Singla A, Gupta R, Saha S, Kumar J, et al. (2017) ${ }^{11}$ who conducted a Crosssectional investigation of mobile usethreat of growing nomophobia Among Students of dental. The association of father's education was found not significant with risk of developing nomophobia. Sanjay Dixit, Harish Shukla, A.K Bhagwat, Arpita Bindal, Abhilasha Goyal, Alia K Zaidi, et al.(2010) ${ }^{12}$ who conducted an investigation to find out mobile addiction in the students of medical college in India. Results showed no association of risk of developing nomophobia with academic sessions. The limitations of this research study was few studies available in the field of mobile usage pattern. Secondly the sample size limited and not containing responses from the students of other professions. 


\section{Conclusion}

In this study one third (31.25\%) of the total students had abnormal mobile usage pattern, which can also be referred as frequent users. The maximum number of students was not at the risk of developing nomophobia. There was a moderate uphill (positive) relationship between the mobile usage pattern and risk of developing nomophobia among students. The calculated $\mathrm{F}$ and $t$ values of age (in years), gender, father and mother education, Family monthly income, type of family and academic year found no significantat $\mathrm{p}<0.05$, which means there was not significant relationship between the variables. Age (in years), gender, father and mother education, Family monthly income, type of family and academic year had no notified relationship with risk of developing nomophobia, whereas the calculated t-value between gender and risk of developing nomophobia had shown significant relations.

Acknowledgement: We owe the gratitude toward our family to hold up throughout this project as well as special thanks to our principal Mrs. Harmeet Kaur Kang for instilling an eager inside for the professional growth.

Financial support and Sponsorship: Self-funded project

Conflict of Interest: Researchers had not conflict of interest

\section{References}

1. RupaniMahir P, Parikh khushali D, Trivedi Atul V, Singh Mahindra P, Patel Ayushi, Vadodariya Bhakti, et al. CROSS-SECTIONAL STUDY ON MOBILE PHONE INVOLVEMENT AMONG MEDICAL STUDENTS OF A TERTIARY CARE TEACHING HOSPITAL OF WESTERN INDIA. National Journal of Community Medicine [Internet]. $2016 \mathrm{Jul}$ [cited 2018Mar 13];7(7):60013. Available from: http://njcmindia.org/ uploads/7-7_609-613.pdf

2. Katharine B. Phone reliant Britons in the grip of nomophobia, The independent. March 31, 2008. Availablefrom: http://www.independent.co.uk/ news/uk//life-style/gadgets-and-tech/news/surveysuggests-half-of-britons-fear-being-without-theirmobile-8784706.html [last accessed on 2018 March 28]

3. A study to analyze relationship between psychological behavioral factors on Whats App addiction among Youth in Jalandhar District in Punjab. Global advanced research journal [Internet]. 2015May [cited 2018Mar13];4(5):203-7. Available from: http://garj.org/garjmbs/5/2015/4/5/a-studyto-analyze-relationship-between-psychologicalbehavioral-factors-on-whatsapp addiction-amongyouth-in-jalandhar-district-in-punjab

4. Telecom Regulatory Authority of India [Internet]. Home | Telecom Regulatory Authority of India | Government of India. [cited 2018Mar28]. Available from: https://main.trai.gov.in/

5. Arumugam B, Sachi S, Nagalingam S. A descriptive study on behaviour associated with mobile phone usage and its effect on health among medical students in chennai. Journal of Evolution of Medical and Dental Sciences. 2014;3(7):159095.

6. Salloju V, Ranjith B. Cross sectional evaluation of nomophobia severity -mobile phone dependency among south Indian pharmacy college students. Adv J Pharm Life sci Res [Internet]. April 2017 [cited 2018 Mar 13]; 5(1): pp 7-12. Available from https:// www.researchgate.net/publication/316107849 CROSS_SECTIONAL_EVALUATION_oF_ NOMOPHOBIA_SEVERITYMOBILE_PHONE_ DEPENDENCY_AMONG_SOUTH_INDIAN_ PHARMACY_COLLEGE_STUDENTS

7. George S, Saif N, Joseph B. A study on the mobile phone usage pattern and its dependence among medical students of a college in Kerala, India. International journal of Research in Medical Sciences. 2017Aug;5(8):3615-19. DOI: http:// dx.doi.org/10.18203/2320-6012.ijrms20173573

8. Kaur A, Sharma P. A study on the mobile phone usage pattern and its dependence among medical students of a college in Kerala, India. A Descriptive Study to Assess the Risk of Developing Nomophobia among Students of Selected Nursing Colleges Ludhiana, Punjab [Internet]. 2015Sep [cited 2018Mar];1(2):1-6. Available from: https:// www.indianjournals.com/ijor.aspx?target=ijor:ijpn $\&$ volume $=1 \&$ issue $=2 \&$ article $=001$

9. Gezgin DM, Cakir O. Analysis of nomofobic behaviors of adolescents regarding various factors. Journal of human science . 2016May;13(2):250119.

10. Mobile phone use pattern and self- reported health problems among medical students. Journal of evolution of medical and dental sciences [Internet]. 
2016Mar [cited 2018Mar];5(21):1116-9. Available from: https://www.jemds.com/latest-articles. php?at_id $=10437$

11. Prasad M, Patthi B, Singla A, Gupta R, Saha S, Kumar JK,Malhi R, Pandita V Nomophobia: A Cross-sectional Study to Assess Mobile Phone Usage Among Dental Students. Journal of clinical and diagnostic research [Internet]. 2017Feb [cited 2018Mar];11(2):ZC34-ZC39. Available from: https://www.ncbi.nlm.nih.gov/pubmed/28384977
12. Dixit S, Shukla H, Bhagwat A, Bindal A, Goyal A, Zaidi A, et al. A study to evaluate mobile phone dependence among students of a medical college and associated hospital of central India. Indian Journal of Community Medicine [Internet]. 2010Apr;35(2):339-41. Available from: https:// www.ncbi.nlm.nih.gov/pmc/articles/PMC2940198 